www.jmscr.igmpublication.org

Impact Factor (SJIF): 6.379

Index Copernicus Value: 79.54

ISSN (e)-2347-176x ISSN (p) 2455-0450

crossrefDOI: https://dx.doi.org/10.18535/jmscr/v6i10.180

Journal Of Medical Science And Clinical Research

\title{
Prevalence of Depression and its Impact on Perceived Social Support in Elderly Hospitalized Patients: A Cross-sectional Hospital-based Study
}

\author{
Authors \\ Dr Lakshimi Borgohain ${ }^{1}$, Dr Himanshu Gupta ${ }^{2}$ \\ ${ }^{1}$ Associate Professor of Psychiatry, Department of Psychiatry, Assam Medical College and Hospital, \\ Dibrugarh \\ ${ }^{2}$ Post graduate trainee, Department of Psychiatry, Assam Medical College and Hospital, Dibrugarh \\ Corresponding Author \\ Dr Himanshu Gupta
}

Post Graduate Trainee, Department of Psychiatry, Assam Medical College, Dibrugarh, 786001, India Email:docgupta79@gmail.com, Mob: 9818930681

\begin{abstract}
Background: Depression is the silent killer of modern era. In India there is sharp increase in elderly population. Substantial number of elderly likely to have physical and mental co-morbidity. Deficit in perceived support can be an important determining factor not only therapeutically but also prognostically. Aims: To evaluate the prevalence of depression in Elderly Hospitalized Patientsand to study its Impact On Perceived Social Supportin these patients.

Methods: A hospital based cross-sectional study conducted in various Departments of Assam Medical College and Hospital with sample size of 109.Newly admitted patients with age more than 60 year were selected through simple random sampling technique and screened for depression through Prime-MD screening tool, then positive cases were confirmed and classified with ICD-10 and Ham-D respectively. Perceived support was assessed by Multidimensional Scale by Zimet, SPSS version 21.0 was used for statistical analysis of obtained data through tests like chi-square, unpaired t-test and ANOVA.

Results: The prevalence of depression was found to be 31.19\%. It was more in in patients who were female, widow/widower, literate and with longer duration of physical illness. Perceived support was significantly poor in all three domains (Family, Friends and Significant Other) in depressed patients and an association was found between severities of depression and decreased perceived support.

Conclusion: Depression is very common in elderly hospitalized patientsand it is associated with poor perceived support whichfollowed decreasing trend as severity of depression increases from mild to very severe. As conceptuallyperceived support can be both cause and effect of depression, so need of hour is to break this vicious cycle as early as possible and to help the elderly in living as good life as possible despite their illnesses and decreasing capacities.
\end{abstract}

Keywords: Depression, Perceived Social Support, Elderly, Hospitalized, Geriatric. 


\section{Introduction}

Depression is the silent killer of modern era. It presents with low mood, loss of interest, decreased energy, guilt feelings, low self-worth, disturbed sleep, disturbed appetite, and poor concentration.. It often becomes chronic or recurrent and leads to significant impairment in an individual's capability to take care of day-to-day responsibilities $^{[1]}$. It is predicted that unipolar depression is going to become the second-most important cause of morbidity across the world by 2020. ${ }^{[2]}$

Ageing of the population is a global phenomenon and it has its own economic, social and political repercussions. India is in a phase of demographic transition. There has been a sharp increase in the number of elderly persons and it has been projected that by the year 2026, the number of elderly people would rise to about 173 million. ${ }^{[3]}$

A substantial number of elderly people today, are likely to have physical and mental morbidity besides having psycho-social problems. Among the various mental disorders of the geriatric population, depression is most common. ${ }^{[4]}$

Globalization, urbanization and modernization have led to weakening of joint family system and erosion of societal values In India. The traditional sense of obligation and duty of the younger generation towards the elderly is being overlooked. The older generation is stuck between the decline in traditional moral values and the absence of an adequate social security system ${ }^{[5]}$

As per WHO, factors responsible for depression in old age are genetic susceptibility, chronic disease, disability, pain, frustration with limitations in activities of daily living, personality trait (dependent, anxious or avoidant), adverse life events (widowhood, separation, divorce, bereavement, poverty, social isolation) and lack of adequate social support. ${ }^{[6],[7]}$

Patients with greater perceived social support may be more likely to have a positive response to treatment ${ }^{[8]}$ Deficits in social support, negative aspects of the social network, and even excessive amounts of support have been studied as risk factors for depression in late life ${ }^{[9]}$

To help the elderly to live as good life as possible despite their illnesses and decreasing capacities is one of our prime responsibilities. There is a dearth of hospital based studies on elderly depression in this part of country. the present study is, therefore, done to find out the prevalence of depression and its severity in elderly hospitalized patients and its association with perceived social support.

\section{Materials and Methods}

The study was carried out in various departments of Assam Medical College and Hospital, Dibrugarh, Assam from June 2017 to May 2018. It received the ethical approval from the Institutional Ethic Committee. It was a crosssectional study with sample size of 109 patients, Newly admitted patients with age more than 60 year were selected through simple random sampling technique. All the elderly patients admitted in various departments on Tuesday and Thursday who fulfills the inclusion criteria were selected and cross-sectional examination was done within 48 hours of admission. An informed consent was obtained from every participant and They were given liberty to withdraw the consent at any point of time.

Inclusion criteria: Patients with age 60 year or more and giving consent for the study.

Exclusion criteria: Patients who were Critically ill, Non-cooperative, substance dependent,

Having cognitive deficit and admitted in Psychiatric ward were excluded.

\section{Tools used}

(1) Informed Consent form.

(2) Semi-structured Proforma for sociodemographic data developed and used in the Department of Psychiatry, Assam Medical College \& Hospital, Dibrugarh, Assam.

(3) Kuppuswamy's Socioeconomic Status Scale. (modified Kuppuswamy scale updated for the year 2017; Jan-2017)

(4) PRIME-MD: Primary Care Evaluation of Mental Disorders screening questionnaire 
for depressive symptoms

(5) International Classification of Diseases, Revision-10 (ICD-10) diagnostic guidelines

(6) Hamilton Depression Rating Scale (HDRS/ HAM-D)

(7) Multidimensional Scale for perceived Social support by Zimet.

(8) Statistical Package for Social Sciences (SPSS for Windows, version 21.0 Chicago, SPSS Inc.) and Microsoft Excel (Redmond, Washington: Microsoft, 2016. Computer Software).

Procedure: Socio-demographic data of each participant was tabulated in the demographic sheet. They were then screened for depression by applying prime MD scale and the diagnosis of depression was made according to ICD 10 guidelines. The severity of depression was then assessed by using Hamilton depression scale.

Perceived Social support was assessed using 'Multidimensional Scale for perceived Social support by Zimet', The semi-structured questionnaire consists of 12 seven point Likert scale items, which are grouped into three domains. Each domain represents a different source of support (Family, Friends and Significant Other).

The analysis of the observed data was done using Statistical Program for Social Sciences (SPSS) version 21 and Microsoft Excel [excel 2016 (v16.0)]. Results on continuous measurements were presented as mean \pm standard deviation and compared using student t-test for two groups and Analysis of Variance (ANOVA) for more than two groups. Discrete data were expressed as number $(\%)$ and were analysed using Chi square test. For all analyses, the statistical significance was fixed at $5 \%$ level ( $p$ value $<0.05$ ).

\section{Results}

Majority of the patients were male (54.13\%) and between 60-64 years age group (54.13\%) . 83.49\% patients were following Hindu religion and $79.82 \%$ patients were married. $52.2 \%$ patients were illiterate and $78.9 \%$ patients belonged to class-4 socioeconomic status. 69.7\% patients were living in Nuclear family. On applying PRIME-MD, $41.28 \% \quad(\mathrm{n}=45)$ of respondents screened positive for depression.

\section{Prevalence of depression}

On confirming the findings of PRIME-MD, $31.19 \% \quad(n=34)$ were found to be satisfying diagnostic criteria for depression according to ICD-10. So prevalence of Depression was $31.19 \%$.

\section{Severity of depression}

The severity of depression was assessed using HAM-D scale. Out of the 34 confirmed cases of depression, $16(14.68 \%)$ were found to be mild grade, $9(8.26 \%)$ were found to be moderate grade, $6(5.5 \%)$ were found to be of severe grade depression, and only $3(2.75 \%)$ subjects were found to be of very severe grade depression.

\section{Depression according to duration of illness}

$68.75 \%$ patients who were having duration of medical illness more than 12 months suffering from depression, while only $24.24 \%$ were having depression who were having medical illness of less than 3 months at the time of assessment. Result was significant ( $p$ value.002) showing association of depression with duration of illness.

\section{Assessment of depression according to sociodemographic variables}

Assessment of depression in the various sociodemographic groups (Table-1) showed that depression was significantly more common in literate ( $\mathrm{p}$ value-0.042). 
Table-1 Assessment of depression according to sociodemographic variables

\begin{tabular}{|c|c|c|c|c|c|}
\hline \multirow{2}{*}{$\begin{array}{l}\text { SOCIO-DEMOGRAPHIC } \\
\text { VARIABLES }\end{array}$} & \multicolumn{2}{|c|}{$\begin{array}{l}\text { DEPRESSION } \\
\text { PRESENT }\end{array}$} & \multicolumn{2}{|c|}{$\begin{array}{l}\text { DEPRESSION } \\
\text { ABSENT }\end{array}$} & \multirow{2}{*}{$P$ value } \\
\hline & $n=34$ & $\%$ & $n=75$ & $\%$ & \\
\hline $\begin{array}{l}\text { Sex: } \\
\text { - Male } \\
\text { - Female }\end{array}$ & $\begin{array}{l}18 \\
16\end{array}$ & $\begin{array}{l}30.51 \\
32.00\end{array}$ & $\begin{array}{l}41 \\
34\end{array}$ & $\begin{array}{l}69.49 \\
68.00\end{array}$ & 0.866 \\
\hline $\begin{array}{l}\text { MaritalStatus: } \\
\text { - } \quad \text { Married } \\
\text { - Unmarried } \\
\text { - Widow/Widower }\end{array}$ & $\begin{array}{l}24 \\
2 \\
8\end{array}$ & $\begin{array}{r}27.59 \\
33.33 \\
50.00\end{array}$ & $\begin{array}{l}63 \\
4 \\
8\end{array}$ & $\begin{array}{r}72.41 \\
66.67 \\
\\
50.00\end{array}$ & 0.204 \\
\hline $\begin{array}{l}\text { TypeofFamily: } \\
\text { - Nuclear } \\
\text { - Joint } \\
\text { - Living alone }\end{array}$ & $\begin{array}{l}21 \\
10 \\
3\end{array}$ & $\begin{array}{l}27.63 \\
37.04 \\
50.00\end{array}$ & $\begin{array}{c}55 \\
17 \\
3\end{array}$ & $\begin{array}{l}72.37 \\
62.96 \\
50.00\end{array}$ & 0.393 \\
\hline $\begin{array}{l}\text { Educational Status } \\
\text { - literate } \\
\text { - Illiterate }\end{array}$ & $\begin{array}{l}20 \\
14\end{array}$ & $\begin{array}{l}38.46 \\
24.56\end{array}$ & $\begin{array}{l}32 \\
43\end{array}$ & $\begin{array}{l}61.54 \\
75.44\end{array}$ & .042 \\
\hline $\begin{array}{l}\text { Occupation Status } \\
\text { - Employed } \\
\text { - Unemployed }\end{array}$ & $\begin{array}{l}15 \\
19\end{array}$ & $\begin{array}{l}28.84 \\
33.33\end{array}$ & $\begin{array}{l}37 \\
38\end{array}$ & $\begin{array}{l}71.15 \\
66.67\end{array}$ & 0.729 \\
\hline
\end{tabular}

Perceived Support with Respect to Presence or Absence of Depression

There was highly significant decrease in mean score of perceived support by depressed patients in all the 3 domains as shown in table no. 2

Table-2 Perceived Support with Respect to Presence or Absence of Depression

\begin{tabular}{|c|c|c|c|c|c|}
\hline \multirow{3}{*}{ PERCEIVED SUPPORT } & \multicolumn{4}{|c|}{ DEPRESSION } & \multirow{3}{*}{$p$ value } \\
\hline & \multicolumn{2}{|c|}{ Present } & \multicolumn{2}{|c|}{ Absent } & \\
\hline & Mean & $\pm S . D$ & Mean & \pm S.D. & \\
\hline Family & 10.29 & 4.39 & 20.85 & 4.63 & $<0.001$ \\
\hline Friends & 12.74 & 3.93 & 21.64 & 2.77 & $<0.001$ \\
\hline Significant Other & 13.15 & 3.77 & 21.20 & 2.54 & $<0.001$ \\
\hline
\end{tabular}

Perceived Support with Respect to Severity of Depression

Perceived support followed significant decreasing trend in all 3 domains with respect to severity of depression from mild to very severe grade of depression .Table-3 shows mean scores of perceived support in various domains among depressed patients with respect to their severity of depression. after applying ANOVA test, $p$ value was found significant in all 3 domains. by 
applying Tukey HSD Post-hoc Test it was found significant in following groups.

Family: Mild vs Severe, Mild vs Very Severe
Friends: Mild vs Severe, Mild vs Very Severe and Moderate vs Very Severe

Significant Other: Mild vs Severe and Mild vs Very Severe

Table-3 Perceived Support with Respect to Severity of Depression

\begin{tabular}{|c|c|c|c|c|c|c|c|c|c|}
\hline \multirow{3}{*}{ Perceived Support } & \multicolumn{8}{|c|}{ SEVERITY OF DEPRESSION (HAM-D) } & \multirow{3}{*}{$p$ value } \\
\hline & \multicolumn{2}{|c|}{ Mild } & \multicolumn{2}{|c|}{ Moderate } & \multicolumn{2}{|c|}{ Severe } & \multicolumn{2}{|c|}{ Very Severe } & \\
\hline & Mean & $\pm S . D$. & Mean & $\pm S . D$. & Mean & $\pm S . D$. & Mean & $\pm S . D$. & \\
\hline Family & 12.81 & 4.34 & 10.00 & 2.60 & 6.83 & 2.40 & 4.67 & 0.58 & 0.0008 \\
\hline Friends & 15.19 & 3.60 & 12.67 & 2.00 & 9.00 & 1.67 & 7.33 & 1.15 & 0.0001 \\
\hline Significant Other & 15.38 & 3.52 & 12.33 & 3.08 & 10.50 & 2.26 & 9.00 & 1.00 & 0.0021 \\
\hline
\end{tabular}

\section{Discussion}

\section{Prevalence of Depression}

In the present study prevalence of depression was found to be $31.19 \%$, prevalence among male was $30.51 \%$ whereas females it was found to be $32 \%$.

Review of prevalence literature of older age depression showing inconsistent result. McCusker J et al 2005 conducted a cross sectional study on 380 elderly inpatients of two acute care hospitals and found prevalence of major depression ranging from $14.2 \%$ to $44.5 \%{ }^{[10]}$ Which corroborates with findings of our study.

Various other studies done in India in spite of been done in community settings, there were much higher prevalence found between range of $27.5 \%$ to $53 \%{ }^{[12],[13],[14],[23]}$. Probably the wide difference in the various prevalence studies is largely due to methodological differences, such as the definition of depression, the sampling strategies and the sample sizes, A possible reason for higher prevalence in the many studies mentioned could be that, they hadn't excluded subjects with cognitive deficit from their studies, which has been excluded from our study.

\section{Bio-social Characteristics of Subjects Gender}

In our study, Depression was observed to be slightly more common among Females than male, prevalence was $32 \%$ in females and $30.51 \%$ in males.Similar results were found in several other
Indian studies $^{\text {[11], [12], [13], [14], [16], }}$ and in world ${ }^{[15]}$ The reasons depression is more common in female may be that compared to men, women may have a stronger genetic predisposition to developing depression, Women are more ruminative than men, that is, they tend to think \& worry about things more, Not only do they have to go work just like men, but they may also be expected to bear the brunt of maintaining a home, bringing up children, caring for older relatives, and putting up with all the sexism and Women live longer than men. Extreme old age is often associated with bereavement, loneliness, poor physical health, and precarity and so with depression.

\section{Marital Status}

In our study highest prevalence of depression was found in Widow/Widower (50\%) and lowest in in Married (27.59\%), intermediate result was in Unmarried patients (33.33\%).marriage is a well known protective factor in depression and our finding corroborates with other studies. ${ }^{[13],[14]}$

\section{Type of Family}

In our study it was found that the elderly living in a joint family or living alone were more likely to suffer from depression more than those living in a nuclear family. Though not statistically significant, our finding does not corroborate with other studies $^{[11],[24],[25]}$ As other studies show nuclear family as risk factor for depression.

Explanation for finding more depression in joint 
family might be due to progressive erosion of societal values In India. Elderly are not given their due respect and their freedom is curtailed in joint family, moreover they have to play a role of caretaker of home as well as children in spite of being physically unwell.

\section{Education}

In our study higher prevalence of depression was found in literate $(38.46 \%)$ than illiterate $(24.56 \%)$, Result was significant statistically showing association of depression with literacy and our finding corroborates with other studies ${ }^{[14],[27]}$. this might be because of more expectation socially and economically by literate patients as well as better understanding of disease process and consequences.

\section{Duration of Physical Illness}

In our study prevalence of depression was higher in patients who were having illness duration more than 12 months $(68.75 \%)$ while it was lower in patients who have illness less than 3 months $(24.24 \%)$. this result was significant statistically showing association of depression with duration of illness. And it corroborates with other studies. $^{\text {[17], [26] }}$

\section{Perceived Support and Depression}

In our study Depression is found to be associated with very poor perceived support by patient in all domains, Moreover as the severity of depression increases from mild to severe the more deterioration of perceived support found, and the association was found to be statistically significant, similar findings were seen in other studies $^{[18],[19], \text { [20], [21], [22] }}$. In india there is no social security system from government, hence elderly have to be dependent financially as well as psychologically on family, friends and society. this dependence increases in presence of comorbid physical illness specially if it is chronic, debilititaing and life threatening. so if elderly does not get or perceive support, it predisposes to depression. moreover lack of perceived support may be both cause as well as effect of depression.

\section{Conclusion}

From our study, it is evident that depression is highly common in elderly hospitalized patients. There was significant decrease in mean scores of perceived support in all 3 domains in depressed subjects, moreover mean scores followed decreasing trend as severity of depression increases from mild to very severe. As deficit in perceived support can be both cause as well as effect of depression so we have to break this vicious cycle to help the elderly in living as good life as possible despite their illnesses and decreasing capacities.

\section{Conflict of interest: Nil \\ Funding: Nil}

\section{Bibliography}

1. Sadock, Benjamin J. Kaplan and Sadock's Synopsis of Psychiatry: Behavioral Sciences/ Clinical Psychiatry $11^{\text {th }}$ edition pg. 347-380

2. Murray CJL, Lopez AD. The Global Burden of Disease: A Comprehensive Assessment of Mortality and Disability from Diseases, Injuries and Risk Factors in 1990 and Projected to 2020., Geneva, Switzerland; World Health Organization, 1996

3. UNICEF-India-Statistics. available from: http://www.unicef.org/infobycountry/ stats_popup 10. html

4. The World Health Organization (2001), World Health Report: Mental Health: New Understanding New Hope. Geneva: The Institute

5. Bhat AK, Dhruvarajan R. Ageing in India: Drifting Intergenerational Relations: Challenges and Options. Ageing \& Society. (2001) 21: 621-640.

6. Nandi DN, Ajmany $S$, Ganguli $H$, Banerjee G, Boral GC, Ghosh A, et al. (1976) The Incidence of mental disorders in one year in a rural community in West Bengal., Indian J Psychiatry. 18: 79-87. 
7. Kennedy GJ, Kelman HR, Thomas C, Wisniewski W, Metz H, Bijur PE etal. Hierarchy of characteristics associated with depressive symptoms in an urban elderly sample. Am J Psychiatry. (1989) 146: $220-5$

8. Thomas E. OxmanJay G. HullSocial Support and Treatment Response in Older Depressed Primary Care Patients, The Journals of Gerontology: Series B, Volume 56, Issue 1, 1 January 2001

9. Nolen-Hoeksema $\mathrm{S} \&$ Ahrens C. Age differences and similarities in the correlates of depressive symptoms. Psychol. Aging. 2002; 17: 116-24.

10. McCusker J, Cole M, Dufouil C, Dendukuri N, Latimer E, Windholz S, et $a l$. The prevalence and correlates of major and minor depression in older medical inpatients. Journal of the American Geriatrics Society 2005; 53 (8): 1344-53

11. Barua A \&NilamadhabKar. Screening for depression in elderly Indian population. Indian Journal of Psychiatry. (2010) AprJun; 52 (2): 150-153.

12. Sinha SP, Shrivastava SR \&Ramasamy J. Depression in an older adult rural population in India. MEDICC Rev 2013; 15: 41-4.

13. Swarnlata B. The Prevalence of Depression among the Rural Elderly in Chittoor District, Andhra Pradesh. J ClinDiagn Res. Jul 2013; 7 (7): 1356-1360

14. Maulik S \&Dasgupta A. Depression and its determinants in the rural elderly of West Bengal: A cross sectional study. Int J Biol Med Res (2012): 1299-302.

15. Ostbye T, Kristjansson B, Hill G, Newman SC \&Brouwer RN. McDowellPrevalence and predictors of depression in elderly Canadians: The Canadian Study of Health and Aging. (2005)

16. Hasche L, Morrow-Howell N, Proctor E. Quality of Life Outcomes for Depressed and Nondepressed Older Adults in
Community Long-Term Care. The American Journal of Geriatric Psychiatry. 2010; 18 (6): 544-553.

17. Murray H, Rosenthal DO. The Challenge of Comorbid Disorders in Patients With Depression. J Am Osteopath Assoc. 2003; 103: 8

18. Wan MohdAzam WM, Din NC, Ahmad M, Ghazali SE, Ibrahim N, Said Z, Ghazali AR, Shahar S, Razali R, Maniam T. Loneliness and depression among the elderly in an agricultural settlement: mediating effects of social support, Asia Pac Psychiatry 2013 Apr; 5 Suppl 1: 134-9

19. Kwag KH, Martin P, Russell D, Franke W, Kohut M, The impact of perceived stress, social support, and home-based physical activity on mental health among older adults, Int J Aging Hum Dev 2011; 72 (2): 137-54

20. Prince MJ, Harwood RH, Blizard RA, Thomas A, Mann AH, Social support deficits, loneliness and life events as risk factors for depression in old age, The Gospel Oak Project VI, Psychol Med 1997 Mar 27 (2): 323-32.

21. Yang Y. How does functional disability affect depressive symptoms in late life? The role of perceived social support and psychological resources. J. Health Soc. Behav. 2006; 47: 355-72.

22. Areán PA, Gum A, McCulloch CE \&Bostrom A, Gallagher-Thompson D, Thompson L. Treatment of depression in low-income older adults. Psychol. Aging. 2005; 20: 601-9.

23. Singh AK, Singh TB, Gupta S \&Yadv, J.S. Prevalence of depression with medical co morbidities among the elderly. Indian J PsychosocSci 2013; 3: 42-7

24. Taqui AM, Itrat A, Qidwai W 7Qadri Z. Depression in the elderly: Does family system play a role? A cross-sectional study. BMC Psychiatry 2007; 7: 57

25. Mason KO. Family change and support of 
the elderly in Asia: What do we know?

Asia Pac Popul J 1992; 7: 13-32

26. Radhakrishnan S \&Nayeem A. Prevalence of depression among geriatric population in a rural area in Tamilnadu. Int $\mathbf{J}$ NutrPharmacolNeurol Dis 2013; 3: 309-12

27. Zhaoyu G. et al. The impact of educational status on the clinical features of major depressive disorder among Chinese women, J Affect Disord. 2012 Feb; 136 (3): 988-992. 